\title{
Features of the Bioconversion of Pentacyclic Triterpenoid Oleanolic Acid Using Rhodococcus Actinobacteria
}

\author{
Natalia A. Luchnikova,2, Polina Yu. Maltseva ${ }^{2}$, Victoria V. Grishkoªnd Irina B. \\ Ivshina ${ }^{1,2, *}$ \\ ${ }^{1}$ Perm Federal Research Center, Ural Branch of the Russian Academy of Sciences, 13aLenin Str., \\ 614990, Perm, Russia \\ ${ }^{2}$ Department of Microbiology and Immunology, Perm State National Research University, 15 \\ Bukirev Str., 614990, Perm, Russia

\section{ORCID}

Natalia A. Luchnikova; 0000-0002-9292-5726

Victoria V. Grishko; 0000-0003-0765-0244

Irina B. Ivshina; 0000-0003-2558-4789

Corresponding Author: Irina B. Ivshina; email: ivshina@iegm.ru

\section{Dates}

Published 13 January 2022

Publishing services provided by Knowledge E

(c) Natalia A. Luchnikova et al. This article is distributed under the terms of the Commons Attribution License, which permits unrestricted use and redistribution provided that the original author and source are credited.

Selection and Peer-review under the responsibility of the 8th Scientific and Practical Conference Conference Committee.
Abstract. The ability of actinobacteria of the genus Rhodococcus to transform oleanolic acid (OA), a plant pentacyclic triterpenoid, was shown for the first time using bioresources of the Regional Specialized Collection of AlkanotrophicMicroorganisms (IEGM; WDCM \#768;www.iegmcol.ru). The most promising strains (R.opacus IEGM 488 and R.rhodochrousIEGM 285) were selected, and these catalyzed $80 \%$ bioconversion of OA $(0.5 \mathrm{~g} / \mathrm{L})$ in the presence of $n$-hexadecane $(0.1 \% \mathrm{v} / \mathrm{v})$ for seven days. The process of OA bioconversion was accompanied by a gradual decrease in the culture medium $\mathrm{pH}$. Adaptive responses of bacterial cells to the OA effects included the formation of compact cellular aggregates, a marked change in the surface-to-volume ratio of cells, and a significant increase in the Zeta potential values. The results demonstrated that the process of OA bioconversion was catalyzed by membrane-bound enzyme complexes. Participation of cytochrome P450-dependent monooxygenases in the oxidation of the OA moleculewas confirmedusing specific inhibitors. The obtained data expand our knowledge on the catalytic activity of actinobacteria of the genus Rhodococcus and their possible use as biocatalysts for the bioconversion of complex hydrophobic compounds. The results can also be used inthe searchfor promising OA derivatives to be used in the synthesis of biologically active agents.

Keywords: bioconversion, oleanolic acid, Rhodococcus, biologically active compounds

\section{Introduction}

The drugs derived from secondary plant metabolites, including pentacyclic triterpenoids, make up about $25 \%$ of the total pharmaceutical market[1]. In nature, pentacyclic triterpenoids are represented by more than 20 structures formed by cyclization of their precursor squalene in the tissues of plants, fungi, marine invertebrates, and algae[2-5]. One of the most common plant pentacyclic triterpenoids is oleanolic acid (OA; Figure 1), which concentration in fruits and leaves of Olea europaeacan reach 
$35 \mathrm{mg} / \mathrm{g}$ dry weight[6, 7]. OA is widely used to producederivatives with pronounced anti-inflammation, antitumor, antimicrobial, antiviral, and anti-diabetic activities[8-12]. Nowadays, valuable OA derivatives are often synthesizedby chemical methods requiring extreme temperatures and acidity, aggressive and expensive reagents, as well as protective groups of the reactive sites of the molecule[13,14]. Alternatively, biologically active derivatives ofOA can be produced via its biological conversion using the catalytic activity of microorganisms. Microbial conversion occursin environmentally friendly conditions with high stereo- and regioselectivity and in one technological stage. Moreover, bioconversion allows modification of molecules in positions that are not available for chemical reagents[15]. However, the processes of OA biological conversion described in the literature have significant disadvantages. Thus, the use of fungi is unsafe and impractical due to their ability to produce mycotoxins and the mycelial growth type [16-18]. The few known processes of bacterial transformation catalyzed by representatives of the genera BacillusandNocardia, with individual strains beingpathogenic, are characterized by relatively low (up to 63\%) level of substrate conversion. In addition, the described bacterial biocatalysts show their activity at OA concentration not exceeding $0.3 \mathrm{~g} / \mathrm{L}[19,20]$. In view of this, a search for non-pathogenic bacterial strains able to catalyze the process of highly effective OA conversion is needed.

One of the microbial groupsextensively explored in modern biotechnology is nonpathogenic actinobacteria of the genus Rhodococcus characterized by a great variety of transformable complex hydrophobic compounds. Due tohigh catalytic activity, metabolic lability and polytrophy, multi-purpose oxygenases, synthesis of biosurfactants, the nonmycelial type of growth and the absence of pronounced pathogenic properties make it promising to use unique metabolic systems of rhodococci for the directed conversion of OA[21-23]. It is worth noting that the ability of Rhodococcusactinobacteria to biologically convert pentacyclic triterpenoid betulinto betulone with pronounced biological activity was previously shown $[24,25]$.

\section{Materials and Methods}

\subsection{Microorganisms}

In this work, 70 strains of Rhodococcusactinobacteria from the Regional Specialized Collection of AlkanotrophicMicroorganisms (IEGM; WDCM \#285; www.iegmcol.ru), belonging to species $R$. aetherivorans(1 strain), R. cercidiphylli(1 strain), R. erythropolis(14 strains), 


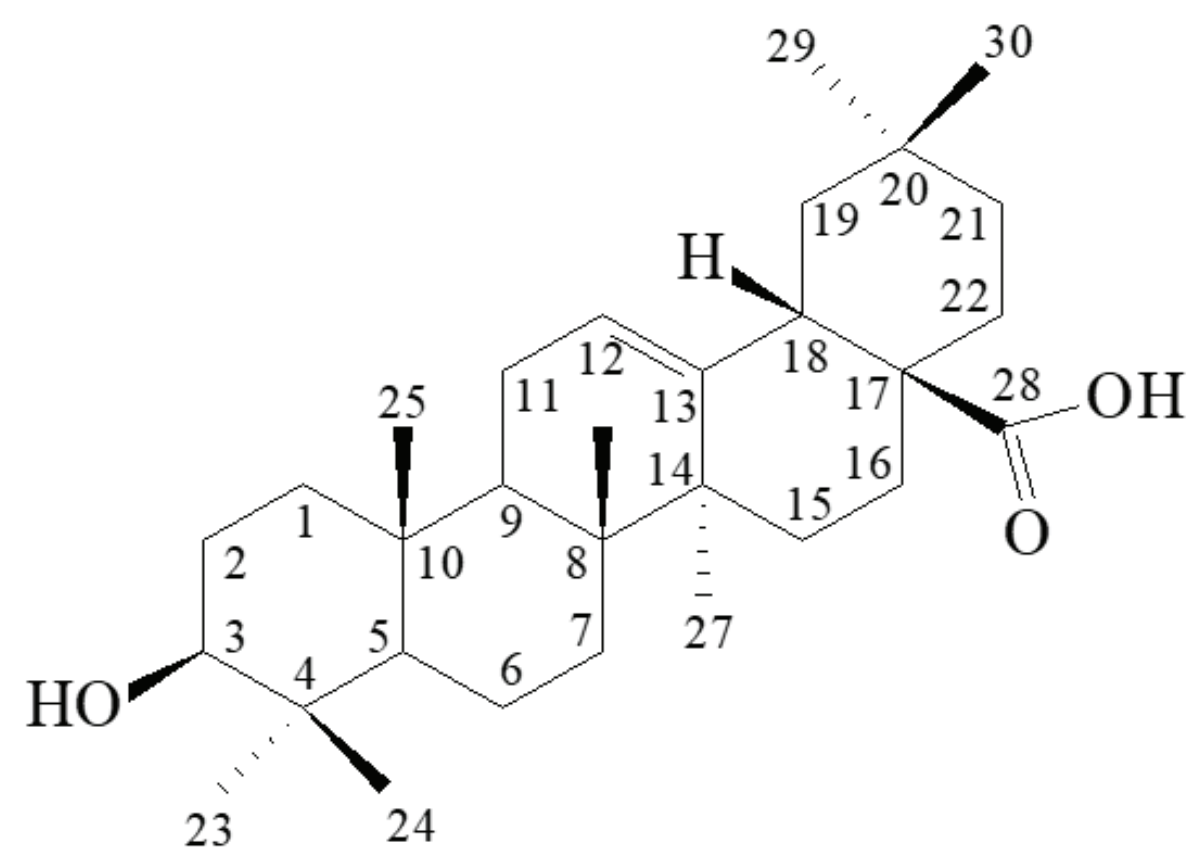

Figure 1: Structure of oleanolic acid.

$R$. fascians(2 strains), $R$. jostii(3 strains), $R$. opacus(15 strains), $R$. qingshengii(2 strains), $R$. rhodochrous(6 strains),and $R$. ruber(26 strains) were used (Table 1).

\subsection{Chemicals}

OA ( $\geq 98 \%, \mathrm{C}_{30} \mathrm{H}_{48} \mathrm{O}_{3}$, CAS 508-02-1, 3ß-hydroxy-olean-12-ene-28-oic acid) purchased from Shanghai Yuanye Bio-Technology Co. (China) was used in the experiments. Ethyl acetate, hexane, and dimethyl sulfoxidewere of the highest commercially available grade (Cryochrom, Russia). n-Hexadecane was purchased from Reachim (Russia). (Trimethylsilyl)diazomethane solution in diethyl ester $(2.0 \mathrm{M})$ was purchased from SigmaAldrich (USA).

\subsection{Cultivation conditions}

Batch cultivation of bacterial cultures was performed in $100 \mathrm{ml}$ Erlenmeyer flasks containing $25 \mathrm{ml}$ of the medium with shaking at $160 \mathrm{rpm}$ on the Sertomat IS orbital shaker (Sartorius, Germany) at $28^{\circ} \mathrm{C}$. In the experiments on bioconversion, the mineral medium of the following composition $\left(\mathrm{g} / \mathrm{L}\right.$ ) was used: $\mathrm{K}_{2} \mathrm{HPO}_{4}-1.0 ; \mathrm{KH}_{2} \mathrm{PO}_{4}-1.0$; $\mathrm{KNO}_{3}-1.0 ; \mathrm{NaCl}-1.0 ; \mathrm{MgSO}_{4}-0.2 ; \mathrm{CaCl}_{2}-0.02$. In addition, yeast extract $(0.1 \mathrm{~g} / \mathrm{L})$, trace element solution $(0.1 \% \mathrm{v} / \mathrm{v})$, and $n$-hexadecane $(0.1 \% \mathrm{v} / \mathrm{v})$ as a co-substrate were used. OA dissolved in dimethyl sulfoxide $(1: 10 \mathrm{mg} / \mu \mathrm{L})$ was added at a concentration of 
TABLE 1: Collection strains used in the work.

\begin{tabular}{|c|c|c|}
\hline Species & No. of strains & Strain number in the collection \\
\hline R.aetherivorans & 1 & IEGM $911^{T}$ \\
\hline R.cercidiphylli & 1 & IEGM 1184 \\
\hline R.erythropolis & 14 & $\begin{array}{l}\text { IEGM } 7^{T} \text {, IEGM 21, IEGM 179, IEGM } \\
\text { 191, IEGM 200, IEGM 202, IEGM 254, } \\
\text { IEGM 266, IEGM 275, IEGM 490, } \\
\text { IEGM 499, IEGM 507, IEGM 687, IEGM } \\
766\end{array}$ \\
\hline R.fascians & 2 & IEGM 39, IEGM 930 \\
\hline R.jostii & 3 & IEGM 30, IEGM 60, IEGM 68 \\
\hline R. opacus & 15 & $\begin{array}{l}\text { IEGM 56, IEGM 57, IEGM 58, IEGM } \\
\text { 59, IEGM 246, IEGM 248, IEGM } 249 \text {, } \\
\text { IEGM 262, IEGM 264, IEGM 488, } \\
\text { IEGM 489, IEGM 717, IEGM 765, IEGM } \\
\text { 1157, IEGM } 2226\end{array}$ \\
\hline R.qingshengii & 2 & IEGM 247, IEGM 267 \\
\hline R.rhodochrous & 6 & $\begin{array}{l}\text { IEGM 66, IEGM 608, IEGM 647, IEGM } \\
\text { 654, IEGM 655, IEGM } 760\end{array}$ \\
\hline R.ruber & 26 & $\begin{array}{l}\text { IEGM 72, IEGM 73, IEGM 74, IEGM 76, } \\
\text { IEGM 79, IEGM 81, IEGM 84, IEGM 86, } \\
\text { IEGM 87, IEGM 90, IEGM 91, IEGM } \\
\text { 92, IEGM 93, IEGM 94, IEGM 107, } \\
\text { IEGM 172, IEGM 219, IEGM 227, IEGM } \\
\text { 229, IEGM 232, IEGM 233, IEGM } \\
\text { 235, IEGM 237, IEGM 239, IEGM 240, } \\
\text { IEGM } 324\end{array}$ \\
\hline
\end{tabular}

$0.5 \mathrm{~g} / \mathrm{L}$. In some experiments, inhibitors of cytochrome P450-dependent oxygenases (ketokonazole, metyrapone) were used at a concentration of $1 \mathrm{mM}[26]$. An inoculated medium without OA was used as the biotic control, an uninoculated medium with $n$ hexadecane and OA was used as the abiotic control.

\subsection{Cell viability test}

Cell viability was determined by staining with iodonitrotetrazolium chloride (INT, SigmaAldrich, USA). $100 \mu \mathrm{L}$ of culture and $50 \mu \mathrm{L}$ of $0.2 \%$ aqueous solution of INT were added to 96-well polystyrene microplates. To completely staining, the samples were incubated at $28^{\circ} \mathrm{C}$ for 24 hours. In comparative experiments to determine the viability of the studied cultures, the optical density of samples was measured by a Multiskan Ascent spectrophotometer (Thermo Electron Corporation, USA). 


\subsection{Phase contrast microscopy}

Cells were visualized using an Axiostar plus optical microscope (Carl Zeiss, Germany) in a phase contrast mode with $\times 1000$ magnification. Bacterial cell sizewas measured using the PixeraPRO 150ES camera (Pixera, USA) and the Video Test-Size 5.0 computer program (Akond, Russia). The volume (V) and area (S) of cells were calculated thing formulas [27]:

$$
\begin{gathered}
V=r^{2} \pi h\left(\mu m^{3}\right) ;(1) \\
S=2 r^{2} \pi+\pi r h\left(\mu M^{2}\right),(2)
\end{gathered}
$$

where $r$ is $1 / 2$ of the cell width;

$\pi$ is 3.14 ;

$h$ is the cell length.

\subsection{Zeta potential measurement}

The bacterial culture pre-grown with or without OA was washed and resuspended in $10 \mathrm{mM} \mathrm{KNO}_{3}$ to $\mathrm{OD}_{600} \mathrm{O} .2$ (Lambda EZ201 spectrophotometer, Perkin-Elmer, USA). The electrokinetic potential of the obtained samples was measured using the ZetaSizer Nano ZS (Malvern Instruments, UK).

\subsection{Preparation of actinobacterial cell fractions}

Actinobacterial cells pre-grown for 2 days in the meat-peptone broth were washed three times and resuspended in the phosphate-alkaline buffer $(\mathrm{pH}$ 7.0). The cell suspension was homogenized using a Soniprep 150 ultrasonic disintegrator (MSE, UK) at the amplitude of $10 \mu \mathrm{m}$ for $45 \mathrm{~min}$ with mandatory water cooling. The cell homogenate was centrifuged at $6,000 \mathrm{rpm}$ and $4^{\circ} \mathrm{C}$ for $15 \mathrm{~min}$ to obtain cytoplasmic enzymes (supernatant) (I). Membrane-bound enzymes were solubilized by resuspending the precipitate in 100 $\mathrm{mL}$ of $1 \%$ Triton $\mathrm{X}-100$ solution (Sigma-Aldrich, USA) in the phosphate-alkaline buffer $(\mathrm{pH} \mathrm{7.0)}$ and stirring on the orbital shaker for $30 \mathrm{~min}$. The supernatant with extracted membrane-bound enzymes (II) was obtained by centrifugation. After sonication, the cell precipitate with enzymes strongly bound to the membrane and non-extractable with a detergent (III) was resuspended in $100 \mathrm{~mL}$ of the phosphate-alkaline buffer $(\mathrm{pH}$ 7.0). The prepared cell fractions included (I) a supernatant with cytoplasmic enzymes; (II) 
a supernatant with extracted membrane-bound enzymes; and (III) a resuspended cell precipitate with non-extractable enzymes.

\subsection{Qualitative and quantitative analysis of $O A$ and its metabolites}

To extract the residual $\mathrm{OA}$ and its possible derivatives, the fermentation medium (25 $\mathrm{mL}$ ) was acidified with $10 \% \mathrm{HCl}$ solution (achieving $\mathrm{pH} 4.0$ ) and extracted three times with an equal volume of ethyl acetate. The quality control was carried out by thin layer chromatography (TLC) on ALUGRAM $^{\circledR}$ XtraSILG/UV $_{254}$ plates (MACHEREY-NAGEL $\mathrm{GmbH} \& \mathrm{Co}$, Germany) in the hexane:ethyl acetate system $(3: 7, \mathrm{v} / \mathrm{v})$ The plates were sprayed with $5 \% \mathrm{H}_{2} \mathrm{SO}_{4}$ and heated for $2-3 \mathrm{~min}$ at $95-100^{\circ} \mathrm{C}$. Detection of the studied compounds was performed at $\lambda=365 \mathrm{~nm}$ (UV irradiator LG/58, Russia). Quantitative analysis was performed by gas chromatography-mass spectrometry (GC-MS) using an Agilent 6890N gas chromatograph with a quartz column and an Agilent MSD 5973N quadrupole mass spectrometer (Agilent Technology, USA). Before GC-MS analysis, the samples were methylated using(trimethylsilyl)diazomethane (Sigma-Aldrich, USA).

\section{Results and Discussion}

\subsection{Screening test}

Rhodococcus actinobacteriastrains from IEGM collection were screened for their ability to catalyze the bioconversion of OA.It was found that most of the studied cultures were not able to use $\mathrm{OA}$ as the sole source of carbon and energy. Only individual strains ( $R$. jostiilEGM 60, $R$. opacusIEGM 246, IEGM 262, IEGM 488, IEGM 1157, $R$. rhodochrousIEGM 66, andR. ruberIEGM 107, IEGM 324) showed catalyticactivities. Of these, strainsR.opacusIEGM 488 and R.rhodochrous IEGM 66exhibitingthe greatest catalytic activity were selected for further experiments. $R$. opacus IEGM 488 was isolated from oil-contaminated water of the UnvaRiver, Perm Krai, Russia. This strain uses $n$ hexadecane and crude oil as sole sources of carbon [28]. Whereas $R$. rhodochrousIEGM 66 transforms thioanisol, forms aggregated with liqiud hydrocarbons ( $n$-hexadecane), catalyzes the oxidation of prohiral sulfides into (S)-sulfoxides, and is resistant to $n$ hexane, ethanol, and heavy metals $\mathrm{Cr}^{6+}(10.0 \mathrm{MM}), \mathrm{Mo}^{6+}(5.0 \mathrm{MM})$. It should be noted that the abovestrain shows high transforming activity towards pentacyclic triterpenoid betulin andcatalyzesthe formation of biologically active betulone [29]. 


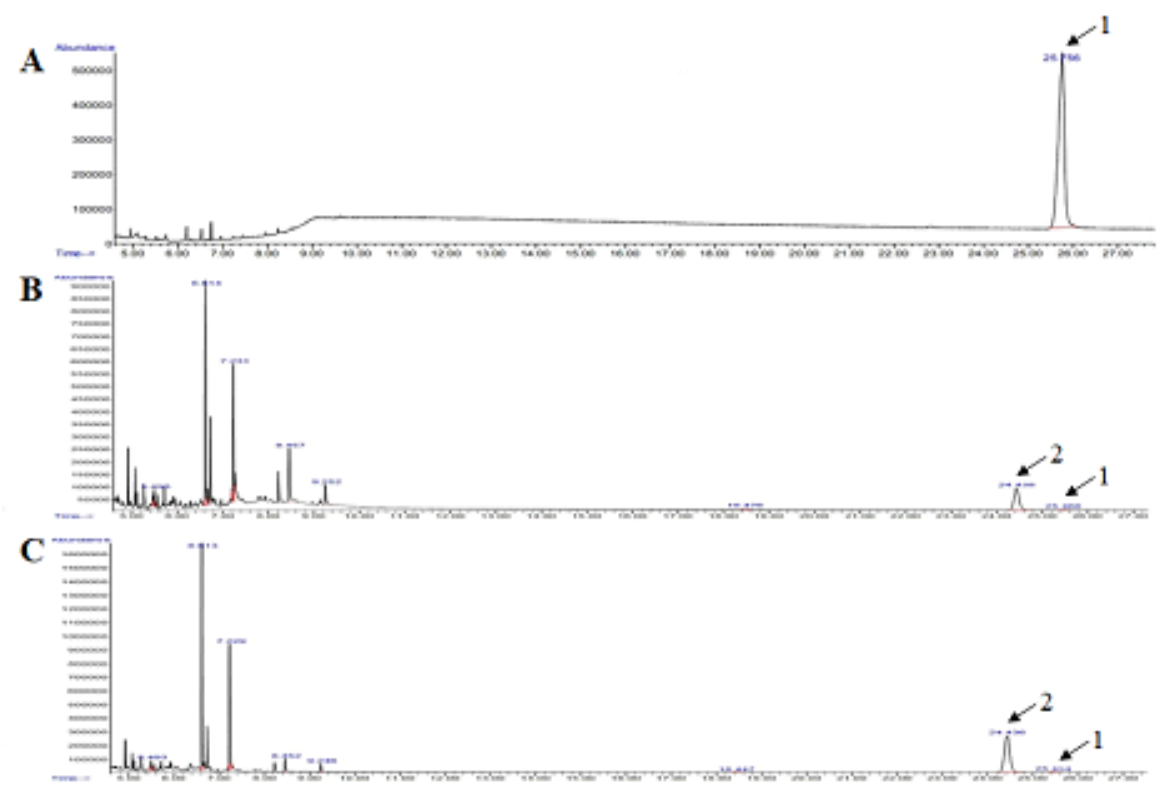

Figure 2: Chromatograms of OA (A) and its bioconversion products usingR.opacus IEGM 488 (B) and R.rhodochrous IEGM 66 (C). 1 - OA, 2 - probable derivative of OA.

\subsection{Bioconversion of OA using R. opacusIEGM 488 R. rhodochrousIEGM 66}

It is known that the use of additional sources of carbon and energy, in particular $n$ hexadecane, can increase the bioconversion efficiency of complex hydrophobic compounds using actinobacteria[25, 30]. According to the dataobtained, R.opacusIEGM 488 andR.rhodochrous IEGM 66 catalyzed $80 \%$ conversion of $0.5 \mathrm{~g} / \mathrm{L}$ OA in the presence of $n$-hexadecane for 7 days (Figure 2). It should be noted that actinobacteriareported in literature showed catalytic activity only at a concentration of OA not exceeding 0.3 $\mathrm{g} / \mathrm{L}$. For example, actinobacteria of the genus Nocardia catalyzed $70 \%$ conversion of $0.3 \mathrm{~g} / \mathrm{L}$ OA for 13 days [19], and actinobacteria of the genus Streptomyces catalyzed $60 \%$ conversion of $0.04 \mathrm{~g} / \mathrm{L}$ OA for 5 days[20].

TheOA biotransformation dynamics was studied.It was found that the maximum conversion level using R.opacus IEGM 488 and R.rhodochrous IEGM 66 occurred on 2 and 4 days of the experiments, respectively (Figure 3A,B). At the same time, the effect of OA on R.opacus IEGM 488 cells was manifested in a pronounced inhibition of their growth compared to biotic control throughout the experiment (Figure $3 \mathrm{~A}$ ). Whereas the addition of OA into the culture medium of R.rhodochrous IEGM 66 did not cause a decrease in the biomass growth (Figure 3B). It should be noted that OA concentration in the abiotic control remained almost unchanged, confirming the biocatalytic nature of the substrate transformation. 

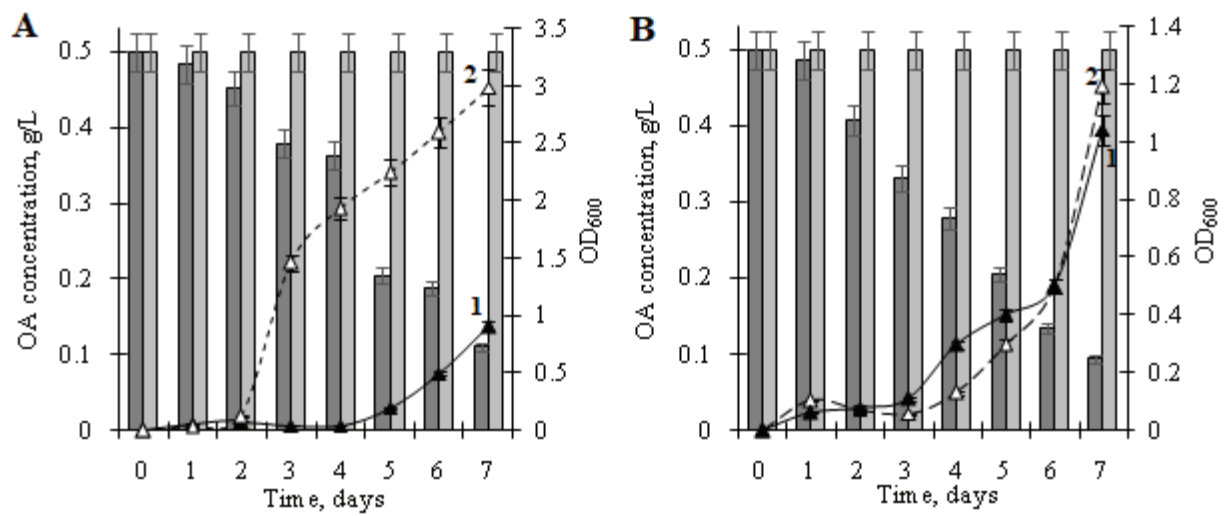

Figure 3: Dynamics of OA biotransformation usingR.opacus IEGM 488 (A) and R.rhodochrous IEGM 66 (B). -OA concentration during biotransformation, - abiotic control, - biotic control.
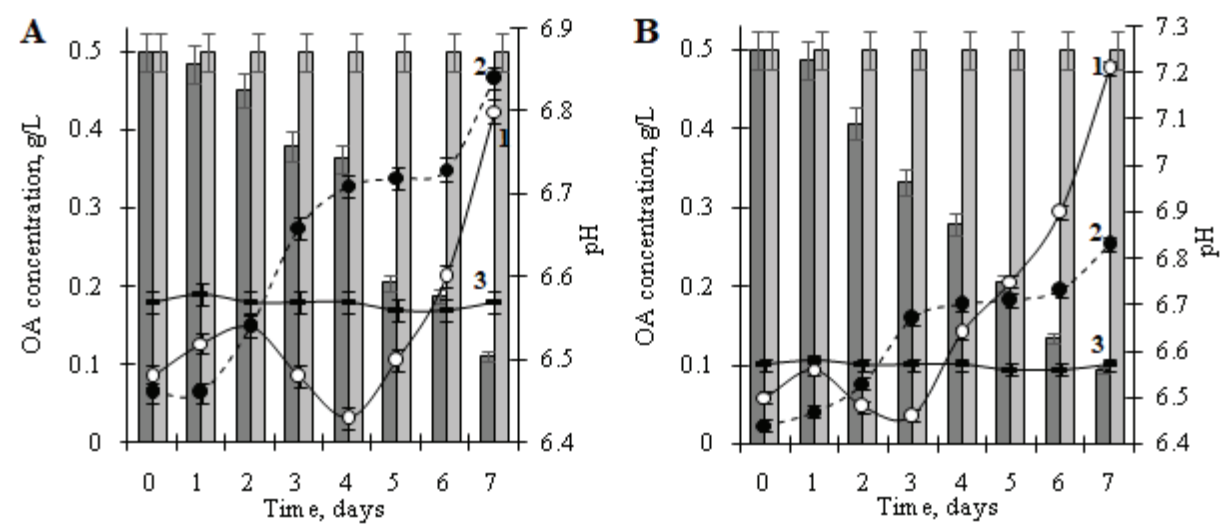

Figure 4: Dynamics of the mediumpH during OA bioconversion (- abiotic control, a- OA concentration during bioconversion, $\mathbf{-}-$ abiotic control.

Studying the dynamics of $\mathrm{pH}$ changes ofthe medium (Figure 4A,B) showed that when rhodococci were cultured in the presence of $n$-hexadecane without $\mathrm{OA}$, the $\mathrm{pH}$ values gradually increased from 6.45 to 6.85 .Itmightbe due to the gradual accumulation of bacterial cell products. Whereas in the presence of $\mathrm{OA}$, the medium $\mathrm{pH}$ ranged from 6.4 to 6.6 in the first 3-4 days, and then dramatically increased to 6.8 in the case of R.opacus IEGM 488 (Figure 4A) and to 7.2 in the case of R.rhodochrous IEGM 66(Figure $4 \mathrm{~B})$. Such changes in the $\mathrm{pH}$ values to low-alkaline may be associated with a decrease in triterpenic acid concentration in the culture medium. The $\mathrm{pH}$ values in the abiotic control were almost unchanged,allowing to inferthat changes in the medium pHare associated with the catalytic activity of rhodococci. 
R. opacus IEGM 488

A

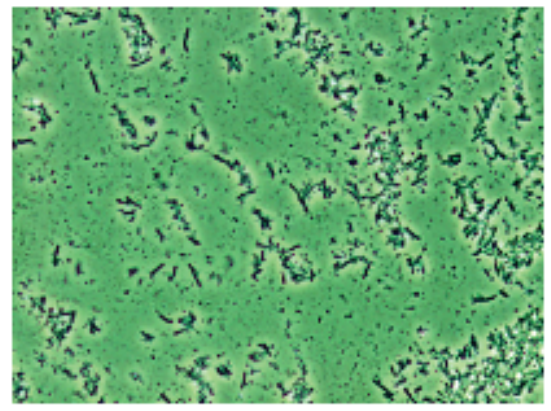

B

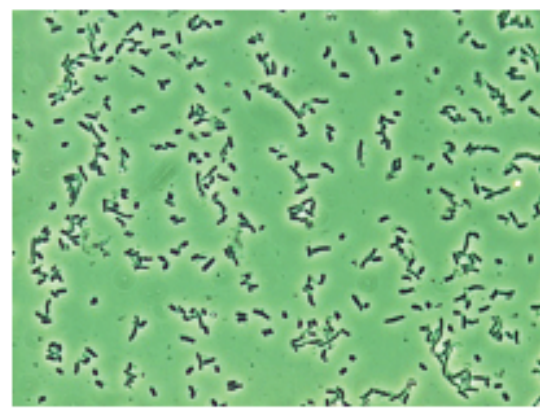

R. rhodochrous IEGM 66

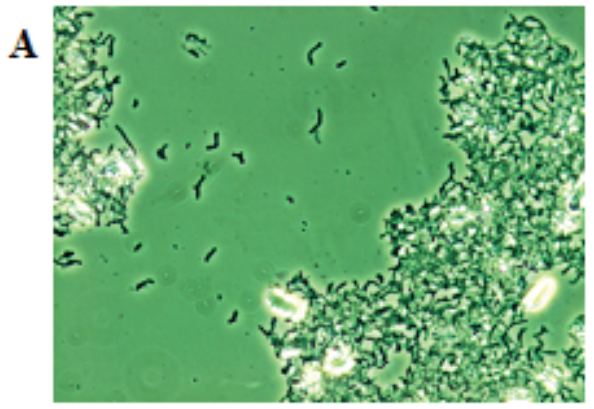

B

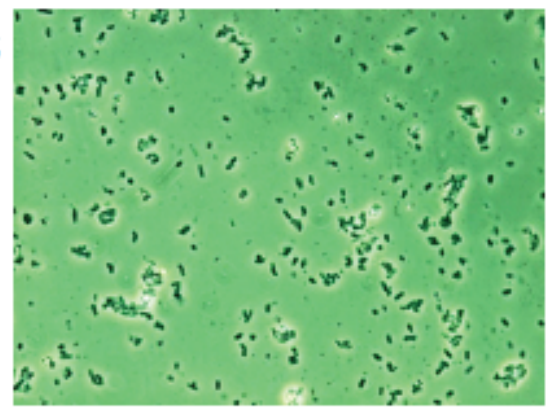

Figure 5: opacus IEGM 488 and R. rhodochrousIEGM 66 in phase contrast (x1000) with (A) or without (B) OA.

\subsection{Effects of OA on Rhodococcus cells}

According to phase-contrast microscopy data, rhodococci formed compact cellular aggregates in the presence of OA (Figure 5). The formation of aggregates seems to enablethe population to adapt and grow in conditions where single cells are not able to reproduce and transform OA.

Analysis ofmorphometric data of OA-exposed cells resulted in detection of changes in the cell length and width, and alsoin surface-to-volume ratio of cells(Table 2 ). In the case of $R$. rhodochrous IEGM 66, an increase in the ratio of cell surface area to cellvolume was detected. According to literature data [27], it promotes a more effective contact of cells with the substrate. Whereas in the case of $R$. opacus IEGM 488, the opposite protective reaction of rhodococciwas observed, tending toreducethe cell surface area availableto contact with OA.

Another reaction of rhodococci to the presence of OA was the changedsurface electrokinetic potential of cells (Table 2). It was found that the addition of OA led to a significant (68\%) increase in the electrokinetic potential of bacterial cells. This Zeta potential shift may be due to possible destabilization of cell membranes influenced by toxicants [31]. 
TABLE 2: Effects of OA on morphological parameters of bacterial cells.

\begin{tabular}{|c|c|c|c|c|c|c|}
\hline $\begin{array}{l}\text { Cultivation } \\
\text { conditions }\end{array}$ & Length, $\mu \mathrm{m}$ & Width, $\mu \mathrm{m}$ & Area $(\mathrm{S}), \mu \mathrm{m}^{2}$ & $\begin{array}{l}\text { Volume } \\
\text { (V), } \mu \mathrm{m}^{3}\end{array}$ & $\begin{array}{l}\text { Relative area } \\
(\mathrm{S} / \mathrm{V}), \mu \mathrm{m}^{-1}\end{array}$ & $\begin{array}{l}\text { Zeta potential, } \\
\mathrm{mV}\end{array}$ \\
\hline \multicolumn{7}{|c|}{ R. opacusIEGM 488} \\
\hline $\begin{array}{l}\text { Medium with } n \text { - } \\
\text { hexadecane }\end{array}$ & $7.19 \pm 0.36$ & $1.93 \pm 0.10$ & $49.42 \pm 2.47$ & $21.02 \pm 1.05$ & $2.35 \pm 0.11$ & $-45.0 \pm 0.05$ \\
\hline $\begin{array}{l}\text { Medium with } n \text { - } \\
\text { hexadecane and } \\
\text { OA }\end{array}$ & $17.13 \pm 0.86$ & $2.52 \pm 0.13$ & $145.52 \pm 7.27$ & $85.42 \pm 4.27$ & $71.71 \pm 0.09$ & $-14.35 \pm 0.07$ \\
\hline \multicolumn{7}{|c|}{ R. rhodochrousIEGM 66} \\
\hline $\begin{array}{l}\text { Medium with } n \text { - } \\
\text { hexadecane }\end{array}$ & $9.61 \pm 0.48$ & $2.84 \pm 0.14$ & $98.35 \pm 4.91$ & $60.83 \pm 3.04$ & $41.62 \pm 0.08$ & $-42.50 \pm 0.57$ \\
\hline $\begin{array}{l}\text { Medium with } n \text { - } \\
\text { hexadecane and } \\
\text { OA }\end{array}$ & $12.28 \pm 0.61$ & $2.59 \pm 0.13$ & $110.40 \pm 5.52$ & $64.66 \pm 3.23$ & $3 \mid 1.71 \pm 0.09$ & $-13.55 \pm 0.07$ \\
\hline
\end{tabular}

TABLE 3: Biotransformation of OA using cell fractions.

\begin{tabular}{|c|c|c|}
\hline Cell fraction & R.opacusIEGM 488 & $\begin{array}{l}\text { R.rhodochrous } \\
\text { IEGM } 66\end{array}$ \\
\hline Whole cells & $+^{*}$ & + \\
\hline Supernatant with cytoplasmic enzymes (I) & - & - \\
\hline $\begin{array}{l}\text { Supernatant with extracted membrane-bound enzymes } \\
\text { (II) }\end{array}$ & + & + \\
\hline $\begin{array}{l}\text { Resuspended cell precipitate with non-extractable } \\
\text { enzymes (III) }\end{array}$ & - & - \\
\hline
\end{tabular}

\subsection{Enzymes involved in the bioconversion of OA}

According to literature data, the reactions of microbial oxidation of triterpenoids involve cholesterol oxidase[32], 3ß-hydroxysteroid dehydrogenase[33], as well as enzymes of the CYP450 family[34, 35]. All these enzymes are localized mainly in the cytoplasm or are associated with the cell membrane. In this work, using cell fractions of rhodococci, it was shown that oxidation of OA was catalyzed by enzymes associated with the cell membrane and extracted with a detergent (Table 3).

Using the inhibitors of cytochrome P450-dependent oxygenase activity, we confirmed the involvement of these enzyme complexes in the process of actinobacterial transformation of OA. In particular, the use of metyrapone and ketokonazole resulted in the complete inhibition of the process of OA transformation, as evidenced by no metabolites in the post-culture liquid (Table 4). 
TABLE 4: Effects of inhibitors of P450-dependent enzymes on the transforming activity of actinobacteria.

Inhibitor
Metyrapone
Ketoconazole

R.opacusIEGM 488

Complete inhibition

Complete inhibition
R.rhodochrous IEGM 66

Complete inhibition

Complete inhibition

\section{Conclusion}

The ability of actinobacteria of the genus Rhodococcus to bioconvertthe plant pentacyclic triterpenoid OA was shown. The comparative analysis of transformationactivities of 70 cultures of different rhodococcalspeciesresulted in selection of R.opacus IEGM 488 and R.rhodochrous IEGM 66. These strains catalyzed the effective (80\%) conversion of a relatively high $(0.5 \mathrm{~g} / \mathrm{L})$ concentration of $\mathrm{OA}$ in the presence of $n$-hexadecane $(0.1 \% \mathrm{v} / \mathrm{v})$ for 7 days. It is worth noting that bacterial biocatalysts reported in literature demonstrated their transformationactivities at a concentration of OA not exceeding $0.3 \mathrm{~g} / \mathrm{L}[19,20]$. It was shown that the process of OA bioconversion using rhodococci was accompanied by a decrease in pHof the cultivation medium of biocatalysts. For the first time, the adaptive responses of rhodococci in the presence of OA were described. Along with the formation of compact cell aggregates, the most typical reactions of actinobacterial cells included a marked change in the surface-to-volume ratio of cells, and a significant increase in the Zeta potential values. Using separate cell fractions, it was found that the conversion of OA was catalyzed by membrane-bound enzyme complexes. Using inhibitors, the involvementof CYP450 family enzymes in the process of OA bioconversion was confirmed. The obtained data expand our knowledge on the catalytic activity of actinobacteria and their possible use as biocatalysts for biotransformation of complex hydrophobic compounds. Being currently searched for are OA derivatives with high prospects in synthesis of biologically active compounds.

\section{Acknowledgments}

The work was supported by the Russian Foundation for Basic Research (grant number 20-34-90104), the Russian Science Foundation (grant number 18-14-00140), was partly carried out within the State Assignments 01201353246and FSNF-2020-0008.

\section{References}

[1] Calixto JB. The role of natural products in modern drug discovery. Anais da Academia Brasileira de Ciencias. 2019;91:1-7. doi: 10.1590/0001-3765201920190105. 
[2] Nursid M, Marraskuranto E, Chasanah E. Cytotoxicity and apoptosis induction of sea cucumber Holothuria atra extracts. Pharmacognosy Research. 2019;11(1):41-46. doi: $10.4103 /$ pr.pr.

[3] Tian M, Zhao P, Li G, Zhang K. In depth natural product discovery from the Basidiomycetes stereum species. Microorganisms. 2020;8:1049-1049. doi: $10.1007 / \mathrm{s} 001289900645$

[4] Chianese G, Golin-Pacheco SD, Taglialatela-Scafati O, et al.Bioactive triterpenoids from the caffeine-rich plants guayusa and maté. Food Research International. 2019;115:504-510. doi: 10.1016/j.foodres.2018.10.005.

[5] Sit NW, Chan YS, Lai SC et al. In vitro antidermatophytic activity and cytotoxicity of extracts derived from medicinal plants and marine algae. Journal de Mycologie Medicale. 2018;28(3):561-567. doi: 10.1016/j.mycmed.2018.07.001.

[6] Romero, Concepción \& Garcia, Aranzazu \& Medina, Eduardo \& Ruiz-Méndez, M. Victoria \& Castro, Antonio \& Brenes, Manuel. Triterpenic acids in table olives. Food Chemistry. 2010;118(3):670-674. doi: 10.1016/j.foodchem.2009.05.037.

[7] Guinda, Ángeles \& Rada, Mirela \& Delgado, Teresa \& Gutiérrez-Adánez, Pilar \& Castellano, Jose. Pentacyclic triterpenoids from olive fruit and leaf. Journal of Agricultural and Food Chemistry. 2010;58(17):9685-9691. doi: 10.1021/jf102039t.

[8] Wiemann J, Heller L, Csuk R. Targeting cancer cells with oleanolic and ursolic acid derived hydroxamates. Bioorganic and Medicinal Chemistry Letters. 2016;26(3):907909. doi: 10.1016/j.bmcl.2015.12.064.

[9] Li R. Huang, Heng Luo, Xiao S. Yang et al. Enhancement of anti-bacterial and antitumor activities of pentacyclic triterpenes by introducing exocyclic $\alpha, \beta$-unsaturated ketone moiety in ring A. Medicinal Chemistry Research. 2014;23(11):4631-4641. doi: 10.1007/s00044-014-1031-z.

[10] Kang H, Ku SK, Kim J, et al. Anti-vascular inflammatory effects of pentacyclic triterpenoids from Astilbe rivularis in vitro and in vivo. Chemico-Biological Interactions. 2016;261:127-138. doi: 10.1016/j.cbi.2016.11.014.

[11] Yu F, Wang Q, Zhang Z, et al. Development of oleanane-type triterpenes as a new class of HCV entry inhibitors. Journal of Medicinal Chemistry. 2013;56(11):4300-4319. doi: 10.1021/jm301910a.

[12] Zou LW, Dou TY, Wang P, et al. Structure-activity relationships of pentacyclic triterpenoids as potent and selective inhibitors against human carboxylesterase 1. Frontiers in Pharmacology. 2017;8:1-12, doi: 10.3389/fphar.2017.00435. 
[13] Chouaïb, Karim \& Romdhane, Anis \& Delemasure, Stéphanie Regiospecific synthesis by copper- and ruthenium-catalyzed azide-alkyne 1,3-dipolar cycloaddition, anticancer and anti-inflammatory activities of oleanolic acid triazole derivatives. Arabian Journal of Chemistry. 2019;12(8):3732-3742. doi: 10.1016/j.arabjc.2015.12.013.

[14] Borkova, L et al. (2017) Synthesis and cytotoxic activity of triterpenoid thiazoles derived from allobetulin, methyl betulonate, methyl oleanonate, and oleanonic acid. CHEMMEDCHEM: CHEMISTRY ENABLING DRUG DISCOVERY.2017;12(5):390-398. doi: $10.1002 / \mathrm{cmdc} .201600626$.

[15] Shah SA, Tan HL, Sultan S et al. Microbial-catalyzed biotransformation of multifunctional triterpenoids derived from phytonutrients. International Journal of Molecular Sciences. 2014;15(7):12027-12060, doi: 10.3390/ijms150712027.

[16] Martinez A, Rivas F, Perojil A, Parra A, Garcia-Granados A, Fernandez-Vivas A. Biotransformation of oleanolic and maslinic acids by Rhizomucor miehei. Phytochemistry. 2013;94:229-237. doi: 10.1016/j.phytochem.2013.05.011.

[17] Gong T, Zheng L, Zhen X, He HX, Zhu HX, Zhu P. Microbial transformation of oleanolic acid by Trichothecium roseum. Journal of Asian Natural Products Research. 2014;16(4):383-386. doi: 10.1080/10286020.2014.884564.

[18] Yan S, Lin H, Huang H, Yang M, Xu B, Chen G Microbial hydroxylation and glycosidation of oleanolic acid by Circinella muscae and their anti-inflammatory activities. Natural Product Research. 2018;6419:1-7. doi: 10.1080/14786419.2018.1477150.

[19] Ludwig, Benjamin \& Geib, Doris \& Haas, Christiane et al. Whole-cell biotransformation of oleanolic acid by free and immobilized cells of Nocardia iowensis: Characterization of new metabolites. Engineering in Life Science. 2015;15:108-115. doi: $10.1002 /$ elsc. 201400121.

[20] Xu, Shaohua \& Wang, Weiwei \& Zhang, Chao \& Liu, Xiu-Feng \& Yu, Bo-Yang \& Zhang, Jian. Site-selective oxidation of unactivated $\mathrm{C}-\mathrm{H}$ sp3 bonds of oleanane triterpenes by Streptomyces griseus ATCC 13273. Tetrahedron. 2017;73(21):3086-3092. doi: 10.1016/j.tet.2017.04.036.

[21] Martínková L, Uhnáková B, Pátek M, Nesvera J, Kren V. Biodegradation potential of the genus Rhodococcus. Environment International. 2009;35(1):162-177. doi: 10.1016/j.envint.2008.07.018.

[22] Kuyukina MS, Ivshina IB. Biology of Rhodococcus. Alvarez HM, editor.Berlin: Springer; 2010.Rhodococcus biosurfactants: Biosynthesis, properties and potential applications.

[23] Ivshina IB, Kuyukina MS, Krivoruchko AV. Microbial resources: From functional existence in nature to applications.Kurtboke I, editor. London: Elsevier Inc.; 2017. 
Hydrocarbon-oxidizing bacteria and their potential in eco-biotechnology and bioremediation.

[24] Tarasova EV, Grishko VV, Ivshina IB. Cell adaptations of Rhodococcus rhodochrous IEGM 66 to betulin biotransformation. Process Biochemistry. 2017;52:1-9. doi: 10.1016/j.procbio.2016.10.003.

[25] Grishko VV, Tarasova EV, Ivshina IB. Biotransformation of betulin to betulone by growing and resting cells of the actinobacterium Rhodococcus rhodochrous IEGM 66. Process Biochemistry. 2013;48(11):1640-1644. doi: 10.1016/j.procbio.2013.08.012.

[26] Yoshida, Keishiro \& Furihata, Kazuo \& Habe, Hiroshi \& Yamane, Hisakazu \& Omori, Toshio. Microbial transformation of $18 \beta$-glycyrrhetinic acid by Sphingomonas paucimobilis strain G5. Biotechnology Letters. 2001;23:1619-1624.

[27] Neumann G, Veeranagouda Y, Karegoudar TB, et al. Cells of Pseudomonas putida and Enterobacter sp. adapt to toxic organic compounds by increasing their size. Extremophiles. 2005;9(2):163-168. doi: 10.1007/s00792-005-0431-x.

[28] Strain Rhodococcus opacus IEGM 488. legmcol.ru 2003/01/01. Available from: http://www.iegmcol.ru/strains/rhodoc/opac/r_opac488.html.

[29] Strain Rhodococcus rhodochrous IEGM 66. legmcol.ru. 2003/01/01. Available from: http://www.iegmcol.ru/strains/rhodoc/rhodoch/r_rhod66.html.

[30] Cheremnykh KM, Luchnikova NA, Grishko VV, Ivshina IB Bioconversion of ecotoxic dehydroabietic acid using Rhodococcus actinobacteria. Journal of Hazardous Materials. 2018;346:103-112. doi: 10.1016/j.jhazmat.2017.12.025.

[31] Halder, Suman \& Yadav, Kirendra \& Sarkar, Ratul et al Alteration of Zeta potential and membrane permeability in bacteria: A study with cationic agents. SpringerPlus. 2015;4(1):1-14. doi: 10.1186/s40064-015-1476-7.

[32] Bastos DZ, Pimentel IC, de Jesus DA, de Oliveira BH Biotransformation of betulinic and betulonic acids by fungi. Phytochemistry. 2007;68(6):834-839. doi: 10.1016/j.phytochem.2006.12.007.

[33] Leipold, Doris \& Wünsch, Gesine \& Schmidt, Melanie et al. Biosynthesis of ursolic acid derivatives by microbial metabolism of ursolic acid with Nocardia sp. strainsproposal of new biosynthetic pathways. Process Biochemistry. 2010;45(7):1043-1051. doi: 10.1016/j.procbio.2010.03.013.

[34] Fujii Y, Hirosue S, Fujii T, Matsumoto N, Agematu H, Arisawa A Hydroxylation of oleanolic acid to queretaroic acid by cytochrome P450 from Nonomuraea recticatena. Bioscience, Biotechnology, and Biochemistry. 2006;70(9):2299-2302. doi: 10.1271/bbb.60126. 
[35] Schmitz D, Zapp J, Bernhardt R. Hydroxylation of the triterpenoid dipterocarpol with CYP106A2 from Bacillus megaterium. Federation of European Biochemical Societies Journal. 2012;279:1663-1674. doi: 10.1111/j.1742-4658.2012.08503.x. 